\title{
Influence of Turbulence Model for Wind Turbine Simulation in Low Reynolds Number
}

\author{
Masami Suzuki \\ Department of Mechanical Systems, University of the Ryukyus, Okinawa, Japan \\ Correspondence should be addressed to Masami Suzuki; m-suzuki@tec.u-ryukyu.ac.jp
}

Received 21 March 2016; Revised 28 July 2016; Accepted 9 August 2016

Academic Editor: Funazaki Ken-ichi

Copyright (C) 2016 Masami Suzuki. This is an open access article distributed under the Creative Commons Attribution License, which permits unrestricted use, distribution, and reproduction in any medium, provided the original work is properly cited.

\begin{abstract}
In designing a wind turbine, the validation of the mathematical model's result is normally carried out by comparison with wind tunnel experiment data. However, the Reynolds number of the wind tunnel experiment is low, and the flow does not match fully developed turbulence on the leading edge of a wind turbine blade. Therefore, the transition area from laminar to turbulent flow becomes wide under these conditions, and the separation point is difficult to predict using turbulence models. The prediction precision decreases dramatically when working with tip speed ratios less than the maximum power point. This study carries out a steadiness calculation with turbulence model and an unsteadiness calculation with laminar model for a three-blade horizontal axis wind turbine. The validation of the calculations is performed by comparing with experimental results. The power coefficients calculated without turbulence models are in agreement with the experimental data for a tip speed ratio greater than 5 .
\end{abstract}

\section{Introduction}

Computational fluid dynamics (CFD) modeling and experiments both have advantages and disadvantages. If both can be done in conjunction, we can expect more effective understanding of the phenomenon. Although CFD is more advantageous for predictions where experiments are difficult to carry out, for example, free stream conditions, it is generally difficult to obtain reliable results compared with experimental data. However, it is possible to obtain useful CFD results with verification by experimental results. Moreover, experiments cannot deliver correct results for any arbitrary condition due to limitations of experimental equipment, measurement errors, and problems with measurement systems. CFD is an efficient tool for turbomachinery and can complement uncertain experimental results [1]. However, CFD simulation generally takes a long time for practical designs. It is necessary to reduce the calculation time for many design conditions.

The Reynolds number of general wind tunnel tests is lower than the one available for turbulence models. Hence CFD with and without a turbulence model have been attempted to solve for wind turbine performance and provide data for various detailed characteristics.
In this paper, they are attempted to solve for more accurate characteristics of a wind turbine in the shortest time possible even on a personal computer, using coarse grid. The reliability of the experimental results and the CFD results are discussed. Furthermore, flow visualization is carried out to obtain more detailed information concerning flow around the blade. The results analyzed by 3 -dimensional CFD simulation are investigated to determine the factors contributing to wind turbine characteristics in detail.

The CFD code is an in-house incompressible finite volume Navier-Stokes solver which was developed by the author. The solver is based on structured grids and the use of curvelinear boundary fitted coordinates. The SIMPLE algorithm is used for pressure-velocity coupling. The convection term is calculated using the QUICK scheme and the other terms in space are calculated using 2nd-order difference schemes. It is well known that sophisticated turbulence models do not always produce better results than the very simple models. Therefore, the proven and computationally efficient LaunderSharma low Reynolds number $k-\varepsilon$ turbulence model is used in this report. Detailed characteristics are solved for by 3dimensional CFD.

The most important points in this research are to make the difference in results between the calculations and the 


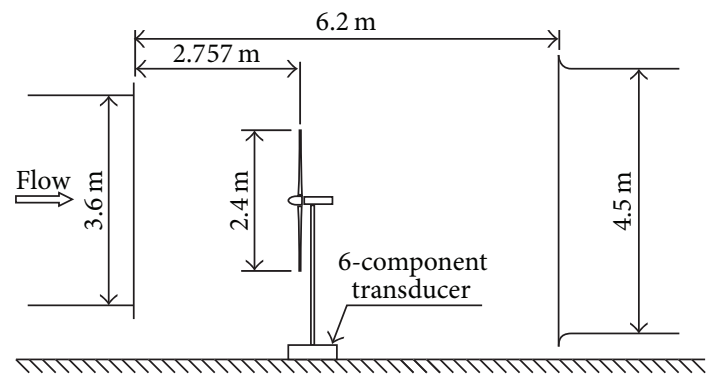

FIGURE 1: Experimental apparatus from Mie University.

experiments clear and to make the calculation results contribute to the improvement of experimental method.

\section{Numerical Methods}

The in-house code used is a self-developed incompressible finite volume Navier-Stokes solver. The solver is based on structured grids and the use of curve-linear boundary fitted coordinates. The grid arrangement is collocated (Perić et al., 1988) [2] and the Rhie and Chow interpolation method (1983) [3] is used. The SIMPLE algorithm (Patankar, 1980) [4] is used for pressure-velocity coupling. The convection term is calculated using the QUICK scheme (Leonard, 1979) [5] and the other terms in space are calculated using 2nd-order difference schemes. It is well known that sophisticated turbulence models do not always produce better results than the very simple models. For practical applications it is often wiser to use a simple approach than the computationally expensive. Therefore, the proven and computationally efficient LaunderSharma low Reynolds number $k-\varepsilon$ turbulence model (1974) [6] is used in this report. In this paper, the calculations with the turbulence model are only steady, and the calculations with the laminar flow model are only unsteady.

2.1. Experimental Condition. Figure 1 shows the experimental apparatus. The experiments of the wind turbine were carried out by Mie University [7]. A three-bladed wind turbine is situated in front of the wind turbine. The experimental wind turbine has a diameter of $2.4 \mathrm{~m}$ and the blades consist of four airfoil profiles as shown in Table 1 . The pitch angle of the tip is $\theta_{\text {tip }}=-2^{\circ}$. The local pitch angle $\theta$ is the twist angle plus the pitch angle of the tip. The internal diameter of the wind tunnel is $3.6 \mathrm{~m}$. The experiment was conducted at a wind velocity of $7 \mathrm{~m} / \mathrm{s}$, and the measured data were the wind velocity, the number of rotation, the torque, and the thrust.

Figure 2 shows the relation of the fluid force acting on the blade element of the wind turbine at radius, $r$; the angle of pitch, $\theta$; the angle of attack, $\alpha$; the lift, $L$; the drag, $D$; the tangential force, $F_{t}$; the axial force, $F_{a}$, that is, thrust force; the wind velocity, $V_{a}$; tip speed, $U=r \Omega$; the rotational speed, $\Omega$; and the relative velocity, $W$. Relations among the lift, $L$, the drag, $D$, the tangential force, $F_{t}$, and the axial force, $F_{a}$, in Figure 2, are written by

$$
\begin{aligned}
& F_{t}=L \sin (\theta+\alpha)-D \cos (\theta+\alpha), \\
& F_{a}=L \cos (\theta+\alpha)+D \sin (\theta+\alpha) .
\end{aligned}
$$

TABLE 1: Wind turbine blade configuration.

\begin{tabular}{lccc}
\hline Radius $(\mathrm{m})$ & Chord of blade $(\mathrm{m})$ & Twist angle $\left(^{\circ}\right)$ & Wing section \\
\hline 1.20 & 0.0850 & 0.00 & NACA63-215 \\
1.08 & 0.0928 & 0.91 & NACA63-215 \\
0.96 & 0.1006 & 1.44 & NACA63-618 \\
0.84 & 0.1084 & 2.86 & NACA63-618 \\
0.72 & 0.1162 & 4.68 & NACA63-618 \\
0.60 & 0.1240 & 5.00 & DU93-W-210 \\
0.48 & 0.1318 & 8.33 & \\
0.36 & 0.1396 & 12.00 & DU91-W2-250 \\
0.24 & 0.1474 & 18.33 & \\
0.12 & 0.0700 & - & Circle \\
\hline
\end{tabular}

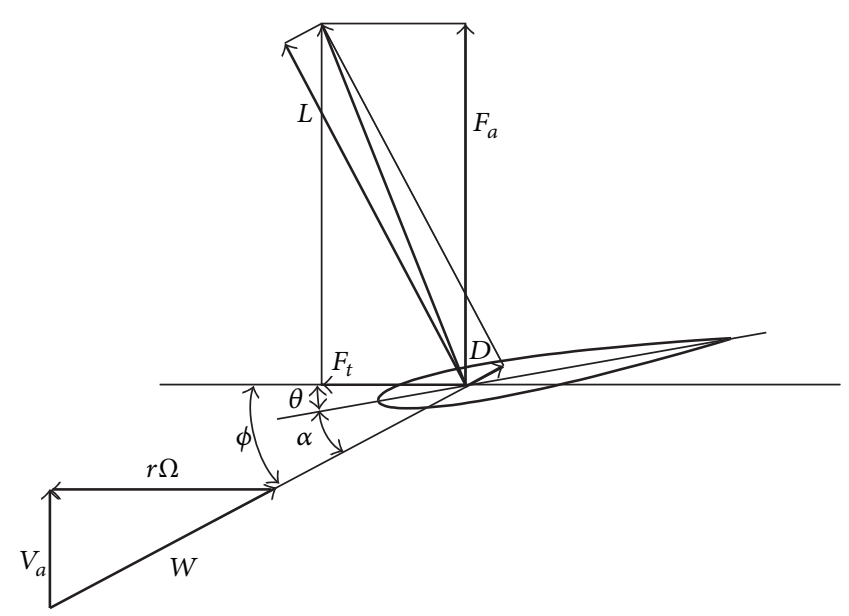

FIgURE 2: Fluid force acting on a blade.

Under no stall conditions, that is, a small angle of attack, (1) is approximated as follows:

$$
\begin{aligned}
& F_{t} \cong L(\theta+\alpha)-D, \\
& F_{a} \cong L .
\end{aligned}
$$

The axial force, $F_{a}$, that is, thrust force, is predicted with the same accuracy as lift. On the other hand, since the tangential force, $F_{t}$, that is, torque, is strongly influenced by drag, $D$, and it serves as the difference of the force by the lift and the drag, the produced force becomes small. For this reason, the predicted accuracy of torque is less than that of the thrust force.

The Reynolds number $\operatorname{Re}=V_{a} R / \nu$ is expressed by the turbine radius, $R$, the wind velocity, $V_{a}$, and the kinematic viscosity of air, $\nu$, and $\operatorname{Re}=6 \times 10^{5}$. The characteristics of the wind turbine are expressed by the tip speed ratio, 


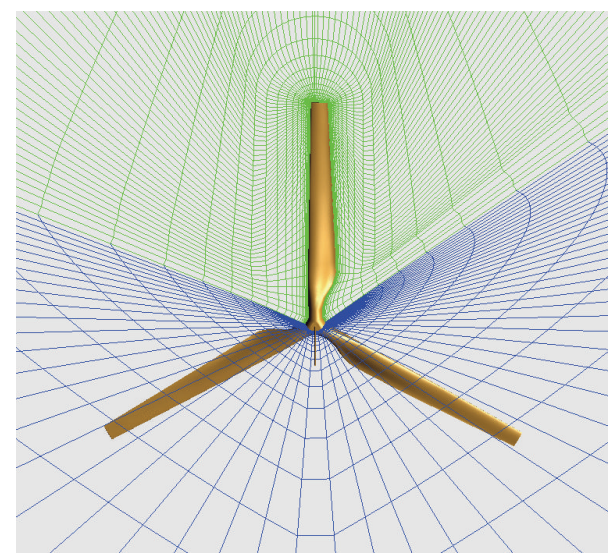

FIgURE 3: 3D computational grid around 3-blade wind turbine.

$\lambda$, the power coefficient, $C_{\mathrm{PW}}$, and the thrust coefficient, $C_{a}$.

$$
\begin{aligned}
\lambda & =\frac{R \Omega}{V_{a}}, \\
C_{\mathrm{PW}} & =\frac{T \Omega}{(1 / 2) \rho V_{a}^{3} \pi R^{2}}, \\
C_{a} & =\frac{F_{a}}{(1 / 2) \rho V_{a}^{2} \pi R^{2}} .
\end{aligned}
$$

2.2. Computational Grid. Figure 3 shows the computational grid around the wind turbine rotor. Periodic boundary conditions are applied to both side surfaces and calculation is performed at the region around one blade, that is, onethird of a sphere domain. The radius of this sphere is twenty times the rotor radius. The $\mathrm{O}-\mathrm{O}$ type grid enables a suitable grid arrangement, being able to arrange many grid points along the wing surface without distributing many points to unnecessary parts. The number of grid points is 130 around the configuration, 63 points spanwise, 52 points normal to the surface direction, and the 425,880 points in total. The grid is generated using an algebraic grid generation method (Eriksson, 1982) [8] based on the transfinite interpolation method which gives $5 \times 10^{-6}$ in a direction normal to the near-wall grid spacing to unit rotor radius and $y^{+}$values of less than 1.0.

\section{General Performance}

In general, the thrust force is nearly equal to the lift, while the tangential force is strongly influenced by drag. Because it becomes the difference of $L \sin (\alpha+\theta)$ and $D \cos (\alpha+\theta)$ from (1), it turns into a small force of less than 10 percent of the thrust force. For this reason, it is easy not only in numerical computation but also in an experiment for large errors to occur in the tangential force result. For the experiment, accurate measurement of the thrust is very difficult, because the experimental apparatus sets up the force transducer on the base under the tower of the wind turbine model. The

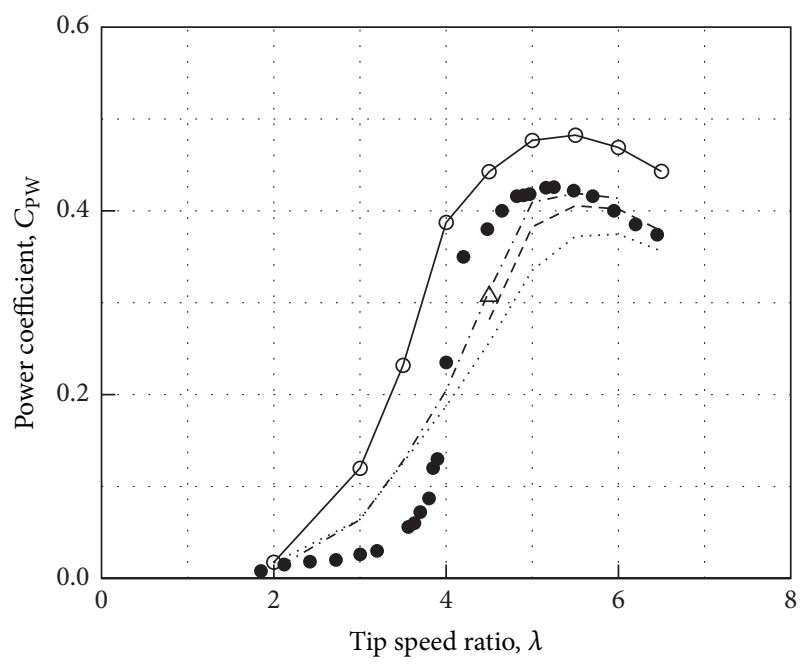

$$
\begin{aligned}
& \bigcirc \operatorname{CFD}(\text { steady } k-\varepsilon) \quad--\Delta t=1 / 8000 \\
& \triangle \Delta t=1 / 32000 \quad \cdots \cdot \Delta t=1 / 4000 \\
& \text {-. } \Delta t=1 / 16000 \text { ○ Exp. (Mie Univ.) }
\end{aligned}
$$

FIgURE 4: Power coefficient compared with experimental data.

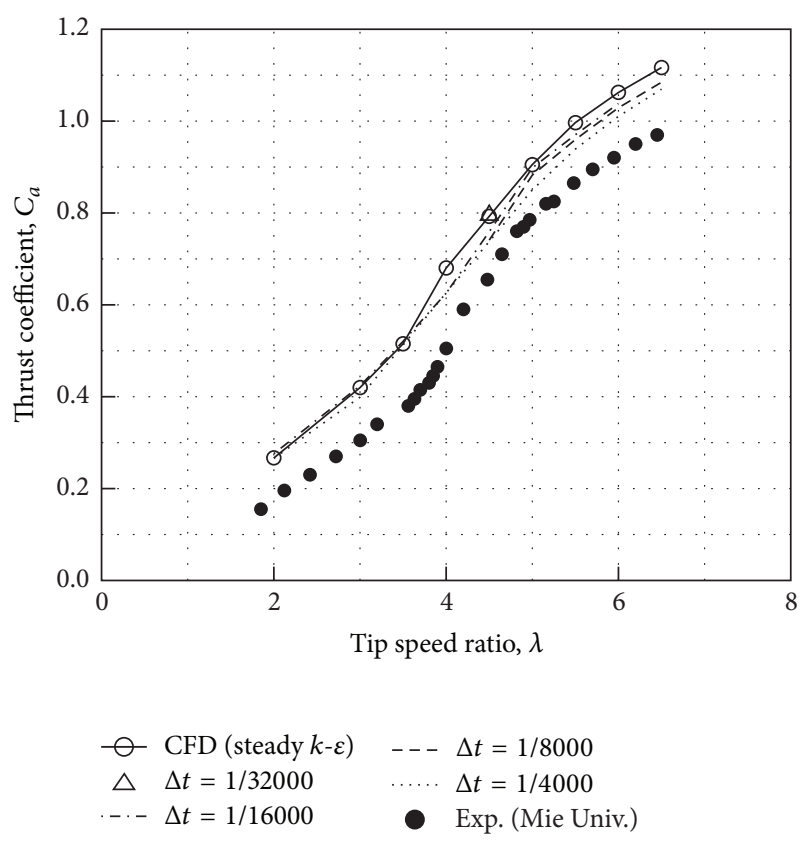

Figure 5: Thrust coefficient compared with experimental data.

force transducer takes the gravitational force and the moment becomes far larger than that of the thrust of the turbine, and the large capacity transducer is selected. The measurement accuracy is thus worsened.

Figures 4 and 5 show the power coefficients and the thrust coefficients, which explain the influence of the $k$ - $\varepsilon$ turbulence model and the time step $\Delta t$ of laminar model. The time steps are $1 / 4000,1 / 8000,1 / 16000$, and $1 / 32000$ rotation. The inflow turbulence intensity is set to $1 \%$ for the $k$ - $\varepsilon$ turbulence model. 


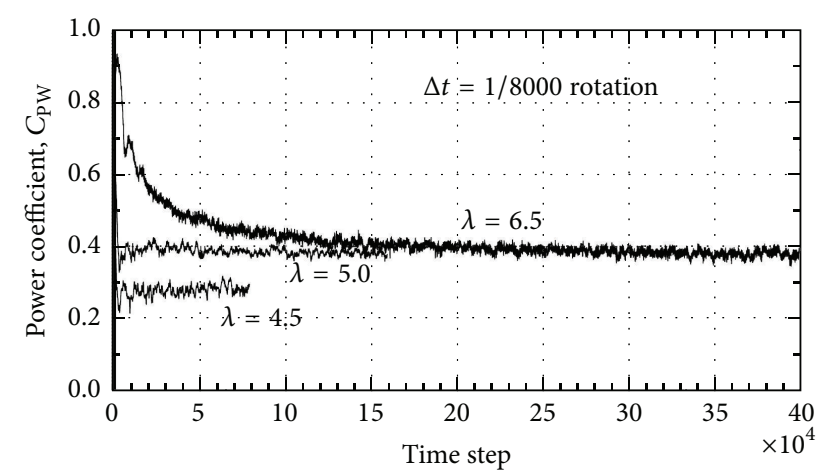

FIgURE 6: Time history of power coefficients.

The solutions have almost converged at the time step that is less than 1/16000 rotation. The power coefficients of the laminar model are in agreement with the experimental results at a tip speed ratio greater than five.

The experimental results show the following characteristics: the maximum power coefficient $C_{\mathrm{PW}}=0.426$ appears at a tip speed ratio of $\lambda=5.25$; the stall region appears below $\lambda=4.2$; the power coefficient decreases above $\lambda=$ 5.5 , because the angle of attack becomes smaller as the tip speed ratio increases. The big difference between the $k-\varepsilon$ turbulence model and the experimental results is produced near just after stall angle where the tip speed ratios are $\lambda=$ $4 \sim 2$. This is because the present turbulence models cannot fully predict the transition from laminar to turbulent flow. In this respect, we anticipate the development of a more accurate turbulence model in the future. Therefore, we attempted to obtain data using the laminar model. In the $k-\varepsilon$ turbulence model, the leading edge separation occurs completely in the region where the tip speed ratio is less than $\lambda=3$. For data obtained at a tip speed greater than $\lambda=5$ in which the angle of attack becomes small so as not to stall, the power coefficients can be fully predicted by the laminar model and are in good agreement with experimental results.

The computational results of the thrust coefficient agree well with the tendency of the experimental results for all regions, displaying an upward shift of about 0.1. The difference 0.1 is very small value for the experiment because it is $0.6 \%$ of full scale of 6 -component force transducer. Therefore, the higher presumed comparison cannot perform to include the large measurement error in this case.

Figure 6 shows the convergence of the unsteady calculation using the laminar model. The results show the tendency for calculations to take a long time as tip speed ratio increases.

\section{Detailed Characteristics}

It is shown in Section 3 that the performance of a wind turbine is predicted with sufficient accuracy in spite of having few grid points. Detailed characteristics, such as the spanwise distribution of characteristics, the flow visualization of blade, and the pressure distribution around the blade, are shown in this section.

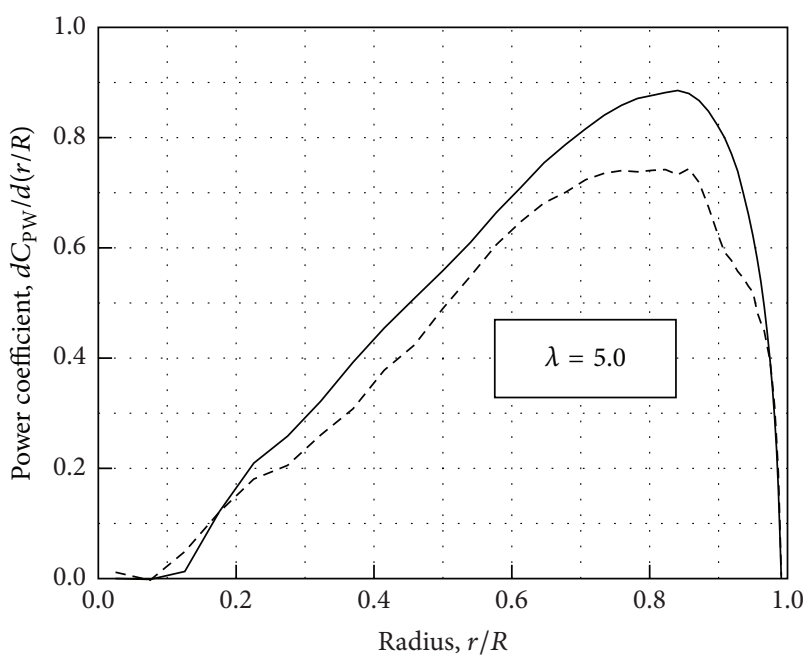

- Steady $k-\varepsilon$

- - $\Delta t=1 / 16000$

FIGURE 7: Local power coefficient for tip speed ratio $\lambda=5$.

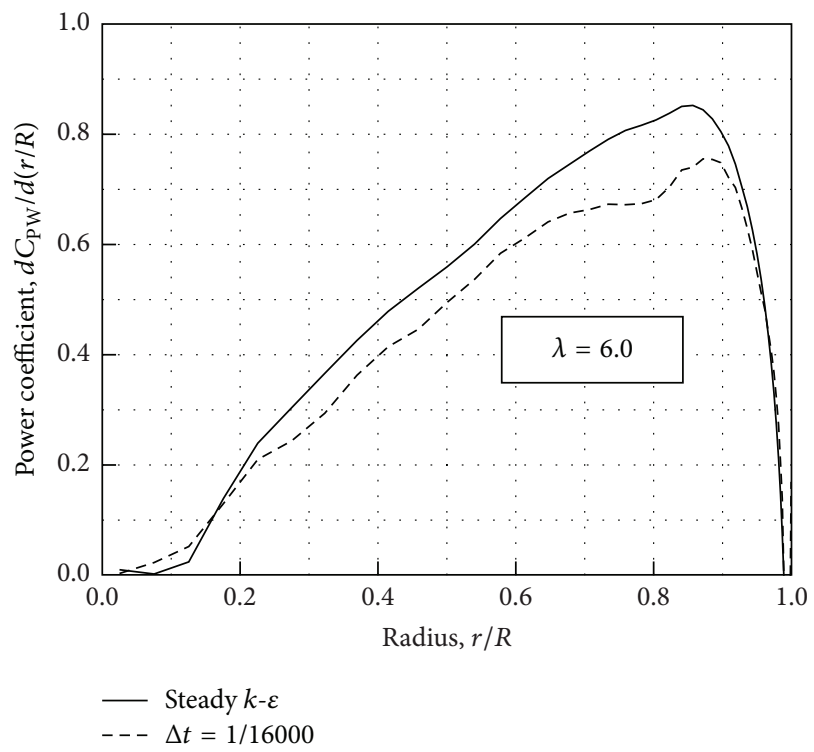

FIGURE 8: Local power coefficient for tip speed ratio $\lambda=6$.

4.1. Characteristics of Spanwise Distribution. Figures 7 and 8 show the spanwise local power coefficients for $\lambda=5$ and $\lambda=6$. The integration of the local power coefficient along the radius presents the power coefficient of (3). The results of the laminar model are lower than the $k-\varepsilon$ turbulence model over the entire span. The results of the laminar model for $\lambda=5$ in Figure 7 show a sudden drop from $r / R=0.86$ to 0.90 . The most different result between the laminar and the $k$ - $\varepsilon$ turbulence model appears at $r / R=0.90$. For $\lambda=6$ in Figure 8 , the most different result between the laminar and the $k-\varepsilon$ turbulence model appears at $r / R=0.80$. The reason for this is the separation near the leading edge in Figures 15 and 17 which is described in detail in Section 4.3. 


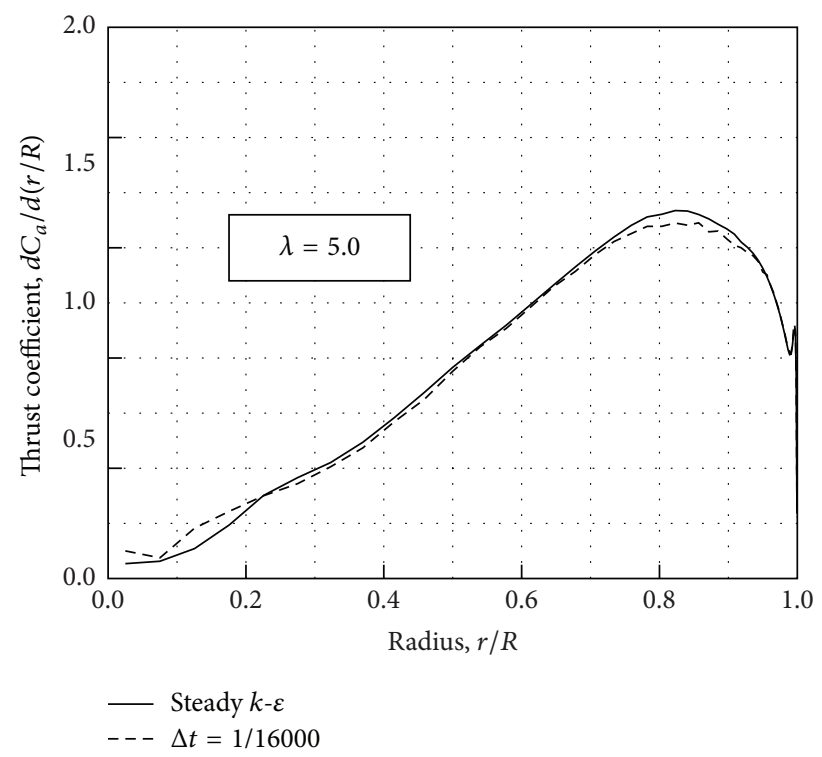

Figure 9: Local thrust coefficient for tip speed ratio $\lambda=5$.

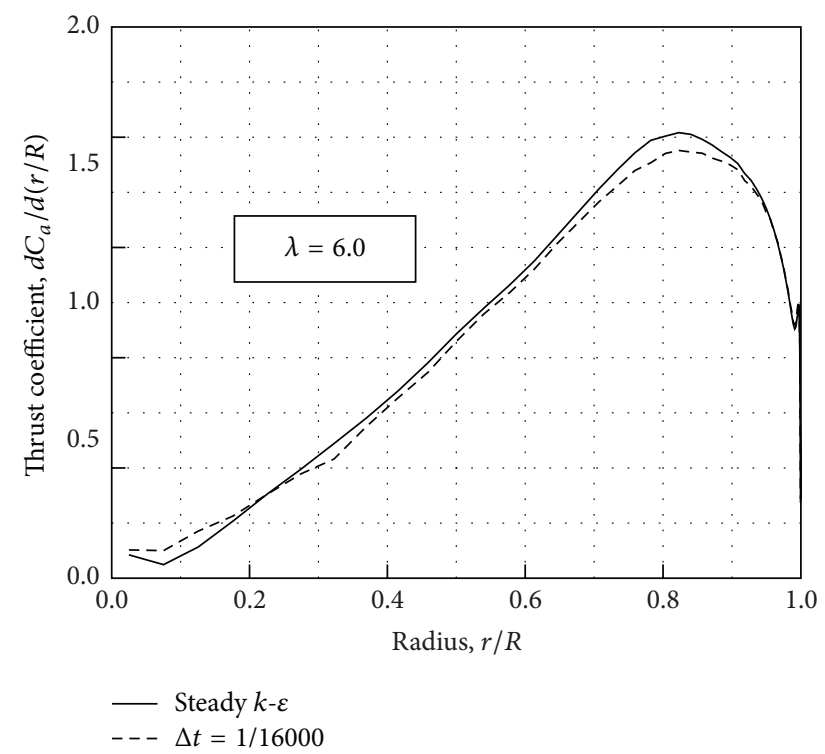

FIGURE 10: Local thrust coefficient for tip speed ratio $\lambda=6$.

Figures 9 and 10 show the spanwise local thrust coefficients for $\lambda=5$ and $\lambda=6$. The integration of the local thrust coefficient along the radius presents the thrust coefficient of (3). The local thrust coefficients are in agreement between the steady calculation of the $k-\varepsilon$ turbulence model and the unsteady calculation of the laminar model. Small differences appear around the $r / R=0.8$ and near the hub.

Figures 11 and 12 show the spanwise axial velocity which is circumferentially averaged at the rotor plane for $\lambda=5$ and $\lambda=6$. The steady calculation of the $k-\varepsilon$ turbulence model and the unsteady calculation of the laminar model almost coincide, because the local thrust coefficients are similar in Figures 9 and 10.

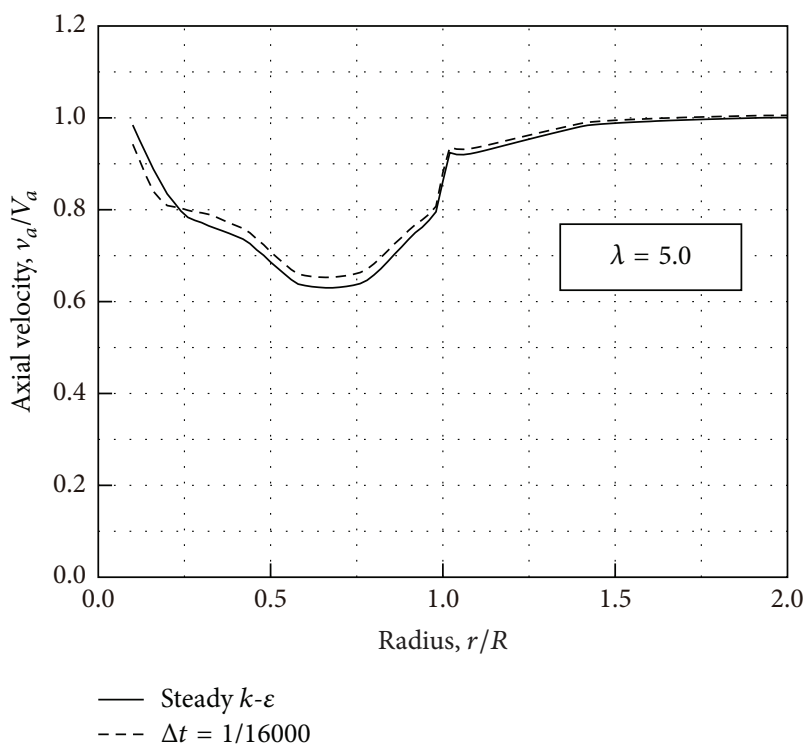

FIgURE 11: Local axial velocity at rotor for tip speed ratio $\lambda=5$.

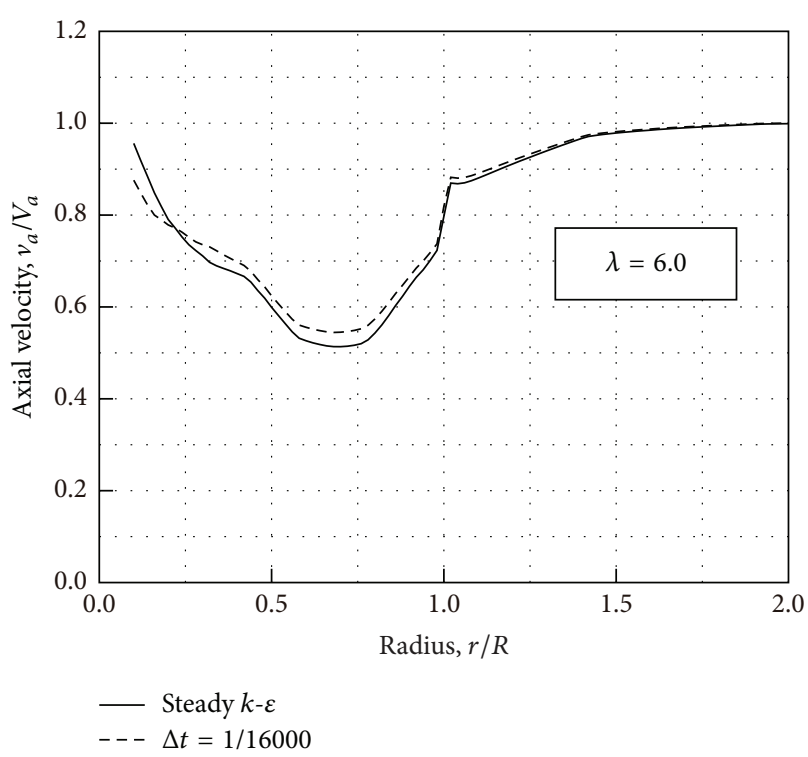

FIgURE 12: Local axial velocity at rotor for tip speed ratio $\lambda=6$.

4.2. Flow around the Blade. Flow visualization of the calculation results is carried out to grasp more detailed information in this section. Figures 13 and 14 show the flows around the blade analyzed using the $k-\varepsilon$ turbulence model. The pressure side experiences a separation bubble from $r / R=0.6$ to 0.82 for $\lambda=5$. The suction sides for $\lambda=5$ and 6 experience trailing edge separation near the hub.

Figures 15 and 16 show the flows around the blade analyzed using the laminar model. The pressure side experiences a separation bubble at $r / R<0.82$ for $\lambda=5$ and all over for $\lambda=6$. The suction side experiences leading edge separation at $r / R>0.85$ for $\lambda=5$ and at chord length of 0.2 around $r / R=0.65$, leading edge separation at $r / R<0.2$. The suction 


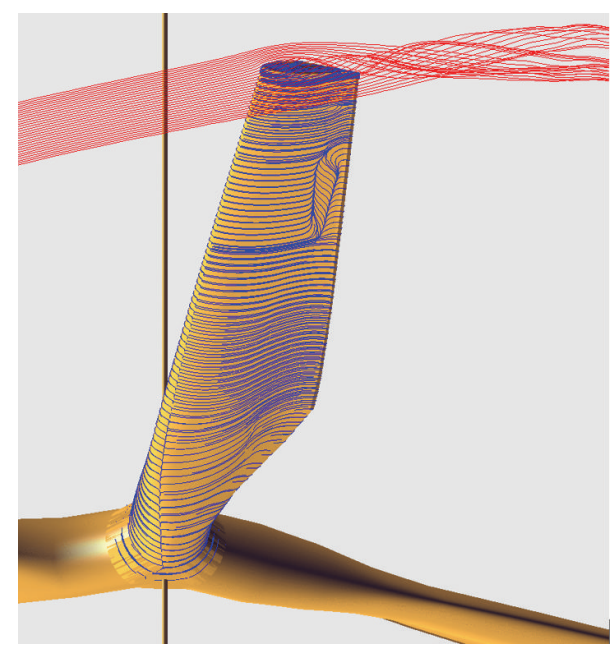

(a) Pressure side

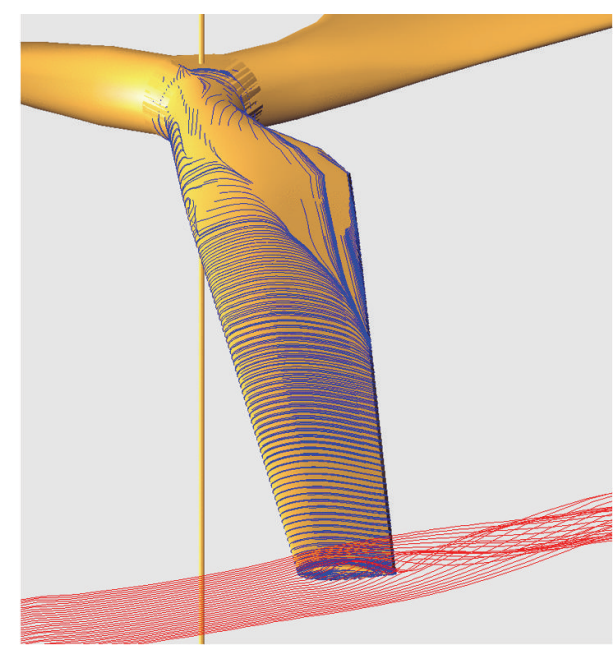

(b) Suction side

FIGURE 13: Limiting streamlines solved on blade surface by the steady $k-\varepsilon$ turbulence model for tip speed ratio $\lambda=5$.

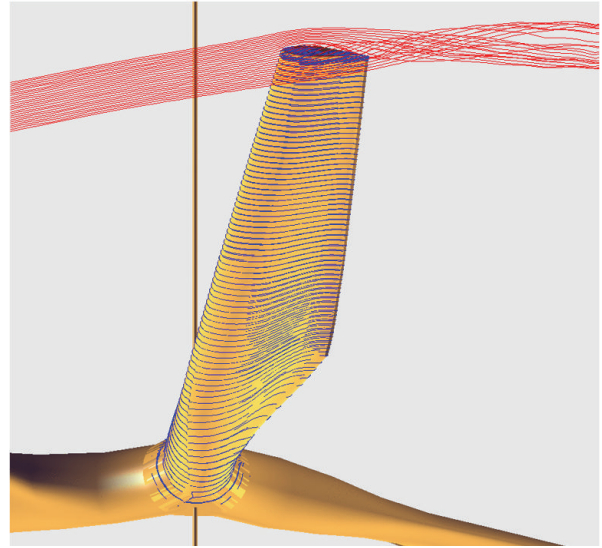

(a) Pressure side

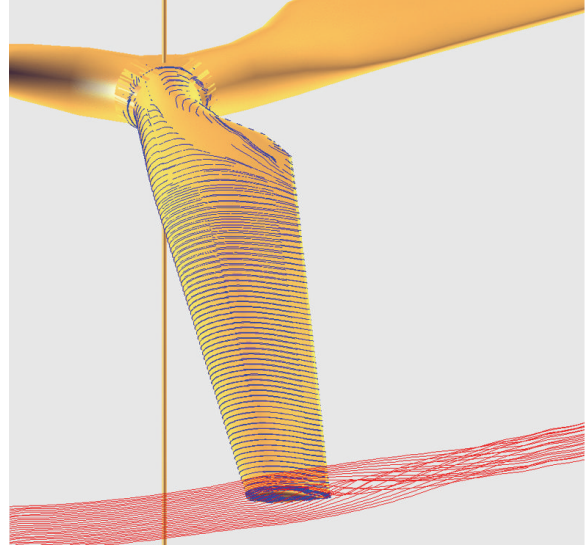

(b) Suction side

FIGURE 14: Limiting streamlines on blade surface solved by the steady $k$ - $\varepsilon$ turbulence model for $\lambda=6$.

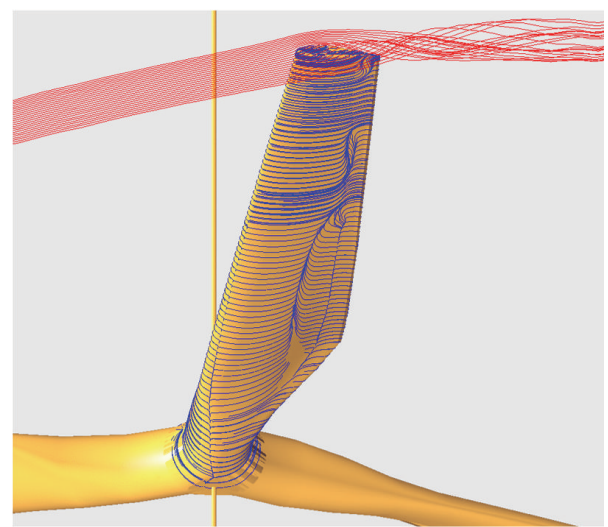

(a) Pressure side

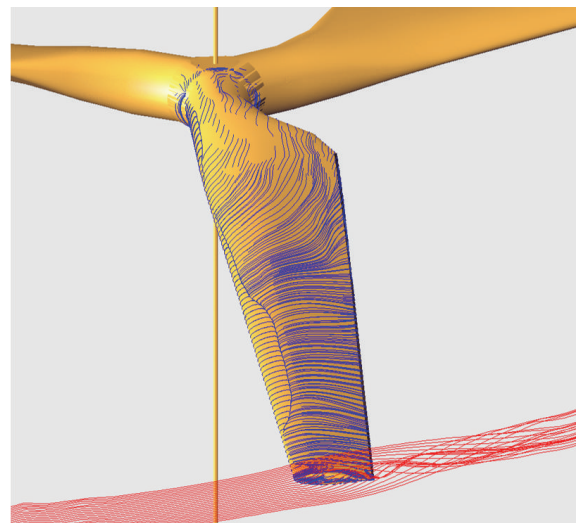

(b) Suction side

FIGURE 15: Limiting streamlines on blade surface solved by the unsteady laminar model $(\Delta t=1 / 16000$ rotation) for $\lambda=5$. 


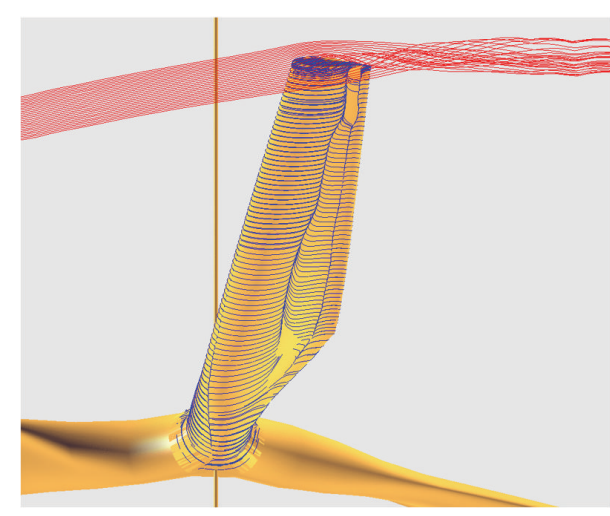

(a) Pressure side

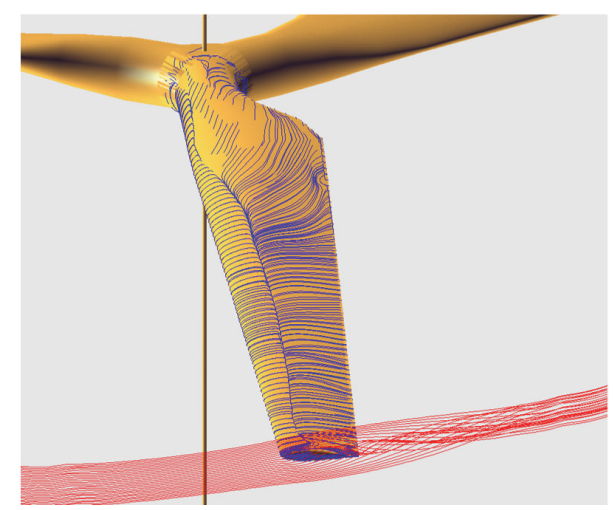

(b) Suction side

FIGURE 16: Limiting streamlines on blade surface solved by the unsteady laminar model $(\Delta t=1 / 16000$ rotation $)$ for $\lambda=6$.

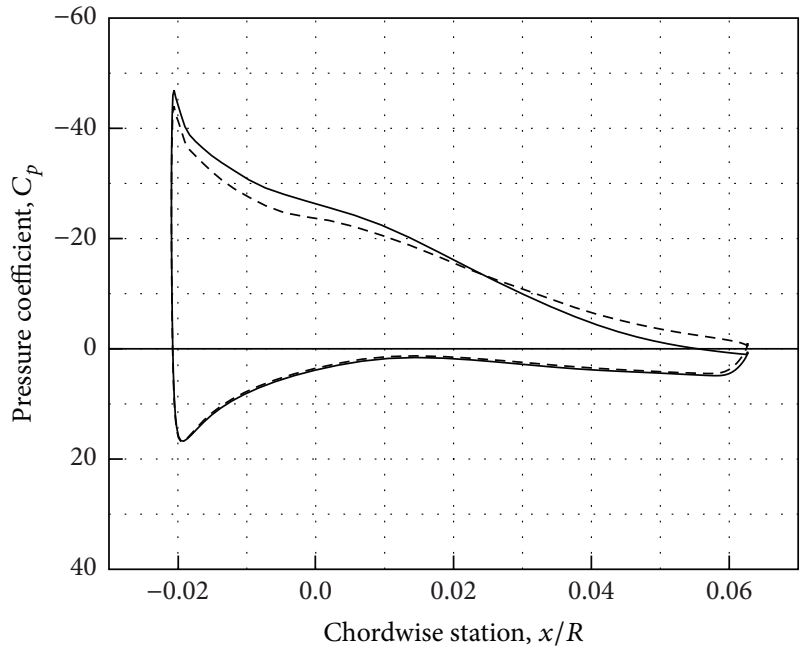

$$
\begin{aligned}
& r / R=0.80, \lambda=5.0 \\
& - \text { Steady }(k-\varepsilon) \\
& --\Delta t=1 / 16000
\end{aligned}
$$

(a) Radius of 0.80

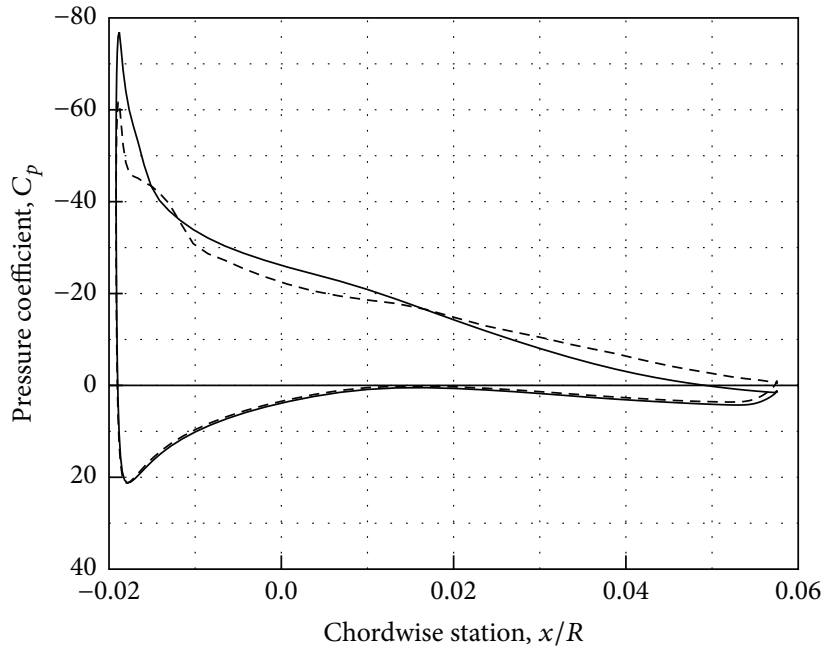

$$
\begin{aligned}
& r / R=0.91, \lambda=5.0 \\
& - \text { Steady }(k-\varepsilon) \\
& \text { - - } \Delta t=1 / 16000
\end{aligned}
$$

(b) Radius of 0.91

Figure 17: Pressure distributions around a blade for $\lambda=5$.

side for $\lambda=6$ experiences separation at the leading edge for $r / R<0.35$ and at chord length of 0.2 for $r / R>0.35$.

4.3. Pressure Distribution on the Blade. This subsection discusses the connection between the pressure distribution on the blade and the separation that is affected by having and not having a turbulence model, while making it correspond to the local power and thrust coefficients, and the flow around the blade. The influences are investigated at a tip speed ratio higher than $\lambda=5$, where the results of the laminar model are in agreement with the experimental results.

Figures 17 and 18 show the pressure distribution on the blade for $\lambda=5$ and 6 . The pressure coefficient $C_{p}$ is expressed by the pressure on the blade $p$, the pressure in main flow $p_{\infty}$, and the wind speed $V_{a}$

$$
C_{p}=\frac{p-p_{\infty}}{(1 / 2) \rho V_{a}^{2}}
$$

The $k-\varepsilon$ turbulence model shows the states in which the separation is not produced; therefore, the pressure drop near the leading edge and the pressure recovery near the trailing edge are sufficiently represented. In contrast, the laminar model shows the states in which the separation is produced; therefore, the pressure drop near the leading edge and the pressure recovery near the trailing edge are insufficiently represented. Therefore, it is shown that the power and thrust coefficients for the laminar model become lower than the $k-\varepsilon$ turbulence model by the separation.

The pressure coefficient on the pressure side between the $k-\varepsilon$ turbulence model and the laminar model does not appear remarkably different, although the small separation exists.

A remarkable difference appears on the suction side. Figure 17(a) shows the pressure coefficients at $r / R=0.80$. The flow of the laminar model is detached at 0.2 chords and the pressure drop at the leading edge and the pressure recovery near the trailing edge become less sufficient than the $k-\varepsilon$ 


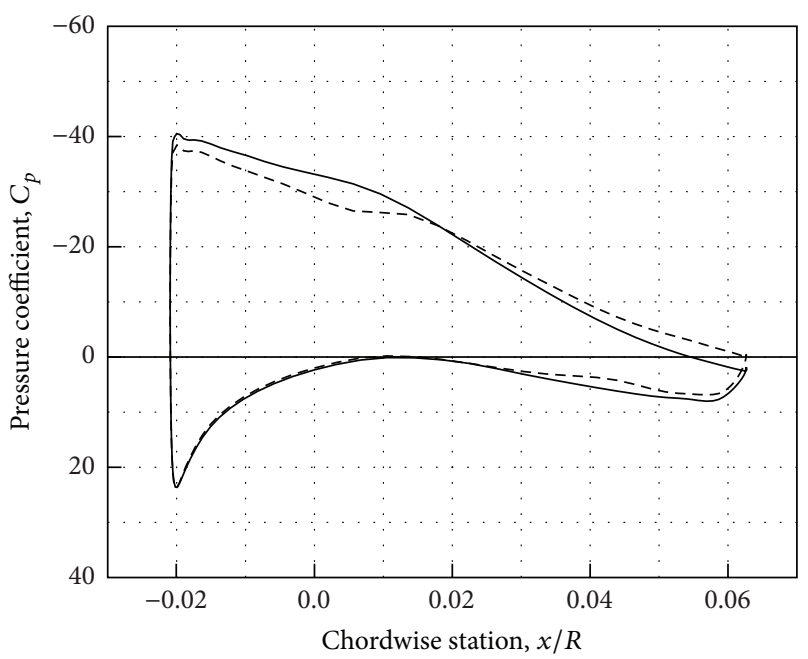

$$
\begin{aligned}
& r / R=0.80, \lambda=6.0 \\
& - \text { Steady }(k-\varepsilon) \\
& ---\Delta t=1 / 16000
\end{aligned}
$$

(a) Radius of 0.80

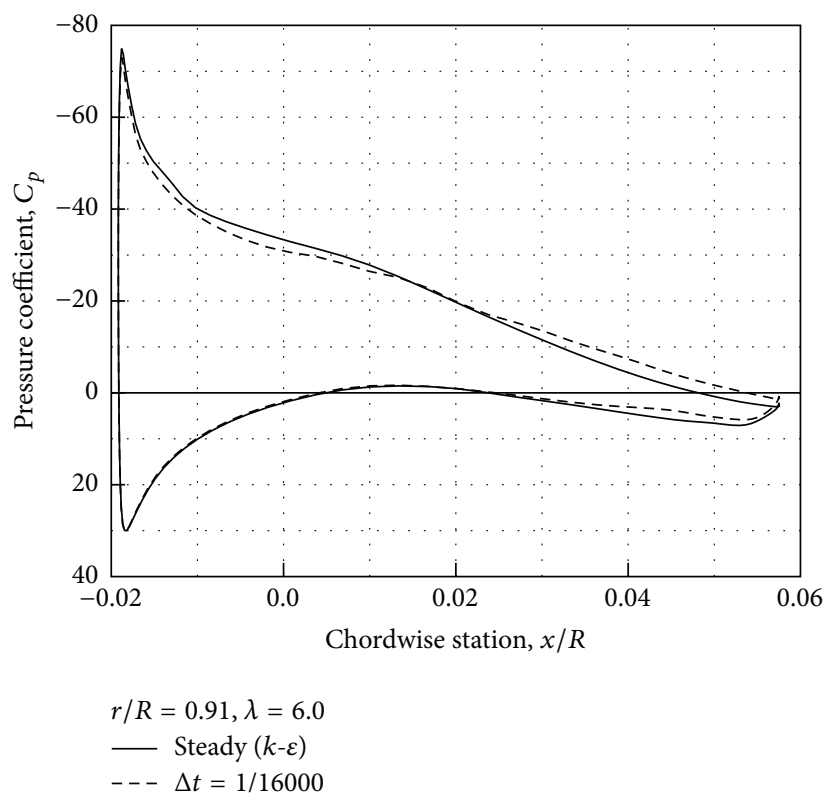

(b) Radius of 0.91

FIGURE 18: Pressure distributions around a blade for $\lambda=6$.

turbulence model, that is, without separation. Figure 17(b) shows the pressure coefficients of $r / R=0.91$. The flow of the laminar model causes the detachment at the leading edge, and there are few pressure drops in the neighborhood of leading edge. The high pressure is maintained from the leading edge to 0.5 chords, and the pressure recovery from 0.5 chords to the trailing edge is not done enough.

The lift is obtained to integrate pressure along the blade surface. It can be understood from the pressure distribution that the difference of the thrust coefficient in Figures 9 and 10 becomes small regardless of whether or not the turbulence model is used. In contrast, a remarkable difference is seen at $r / R=0.91$ in the power coefficient in Figure 7, because the pressure drop at the leading edge and the pressure recovery at the trailing edge have a big influence on the rotational force. Since the flow detachment from the leading edge is not produced for $\lambda=6$ in Figure 8, the same remarkable difference at $r / R=0.91$ such as $\lambda=5$ is not seen. Although there is the influence with and without separation, the pressure distribution on the blade between the $k-\varepsilon$ turbulence model and the laminar model does not appear drastically different and the separation bubbles are very thin such as that shown in Figure 19. Therefore, a similar tendency appears in the power coefficient and the thrust coefficient in Figures 710.

In the calculation of the laminar model, it has been suggested that it may be possible to acquire proper results at a tip speed ratio higher than $\lambda=5$. However, it takes many calculation times.

\section{Conclusions}

The calculation results have been obtained in agreement with the experiment in spite of using the coarse grid in

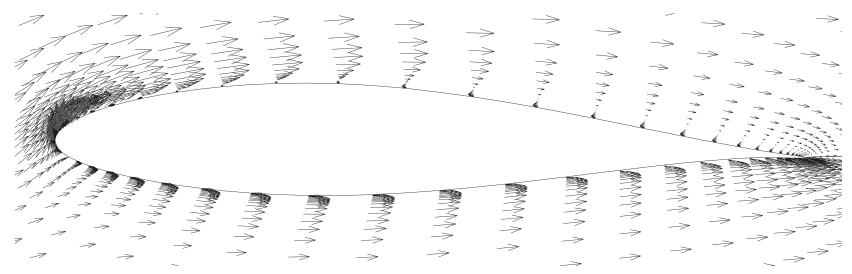

FIGURE 19: Very thin separation bubble solved by the unsteady laminar model at $r / R=0.91$ for $\lambda=5$.

this study. The calculation grid is very coarse; thus, there is a question of whether the turbulence phenomenon can be expressed accurately enough in representing the physical shape. However, the utility value is high if one considers the practical use of calculations which solves the force acting on the blade with precision. The unsteady laminar model is useful for the performance prediction of low Reynolds number systems such as model tests and small wind turbines. The thrust coefficients have little influence whether tests are performed with or without a turbulence model. On the other hand, the power coefficients are sensitive to the presence of a turbulence model, because the pressure at the leading edge and trailing edge are strongly influenced by the separation.

\section{Competing Interests}

The author declares that there is no conflict of interests regarding the publication of this paper.

\section{Acknowledgments}

The work has been supported in part by Harada Memorial Foundation and the Grant-in-Aid for Scientific Research 
(C) no. 24561058 from Japan Society for the Promotion of Science.

\section{References}

[1] M. Suzuki, "Evaluation of experimental results for wind turbine characteristics by CFD," in Proceedings of the 9th International Symposium on Experimental and Computational AeroThermodynamics of Internal Flows (ISAIF '09), CDROM, Paper No.1D-2, Gyeongju, Republic of Korea, 2009.

[2] M. Perić, R. Kessler, and G. Scheuerer, "Comparison of finitevolume numerical methods with staggered and colocated grids," Computers \& Fluids, vol. 16, no. 4, pp. 389-403, 1988.

[3] C. M. Rhie and W. L. Chow, "Numerical study of the turbulent flow past an airfoil with trailing edge separation," AIAA Journal, vol. 21, no. 11, pp. 1525-1532, 1983.

[4] S. V. Patankar, Numerical Heat Transfer and Fluid Flow, McGraw-Hill, New York, NY, USA, 1980.

[5] B. P. Leonard, "A stable and accurate convective modelling procedure based on quadratic upstream interpolation," Computer Methods in Applied Mechanics and Engineering, vol. 19, no. 1, pp. 59-98, 1979.

[6] B. E. Launder and B. I. Sharma, "Application of the energydissipation model of turbulence to the calculation of flow near a spinning disc," Letters in Heat and Mass Transfer, vol. 1, no. 2, pp. 131-137, 1974.

[7] H. Fujioka, Study on characteristics of wind turbine concerning yow and pitch angle [M.S. thesis], Mie University, Tsu, Japan, 2007 (Japanese).

[8] L. E. Eriksson, "Generation of boundary conforming grids around wing-body configurations using transfinite interpolations," AIAA Journal, vol. 20, no. 10, pp. 1313-1320, 1982. 


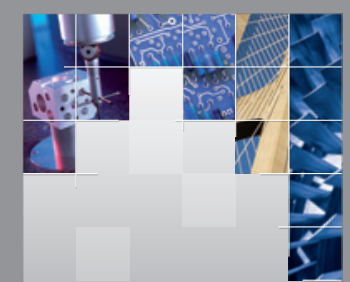

\section{Enfincering}
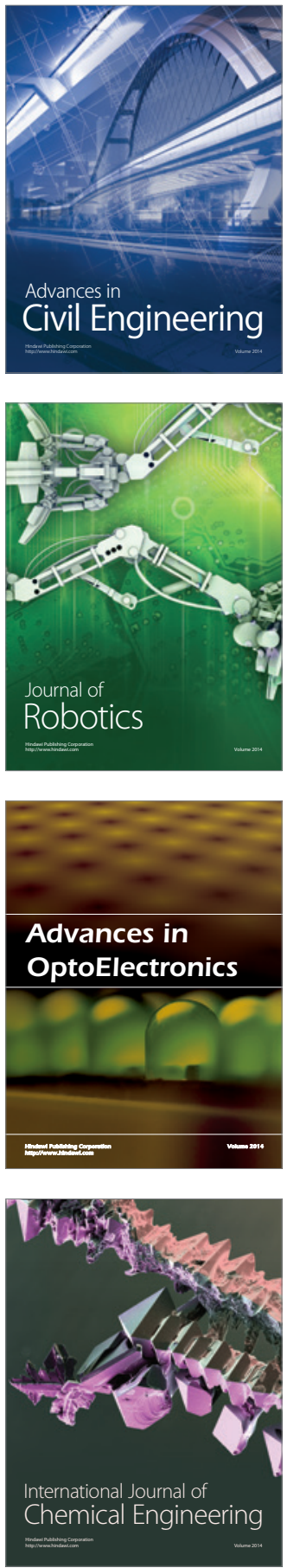

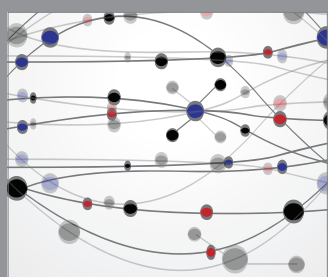

The Scientific World Journal

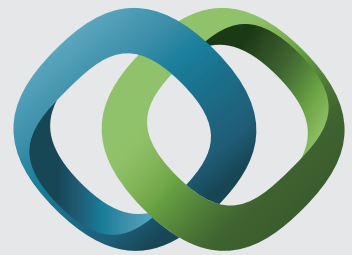

\section{Hindawi}

Submit your manuscripts at

http://www.hindawi.com
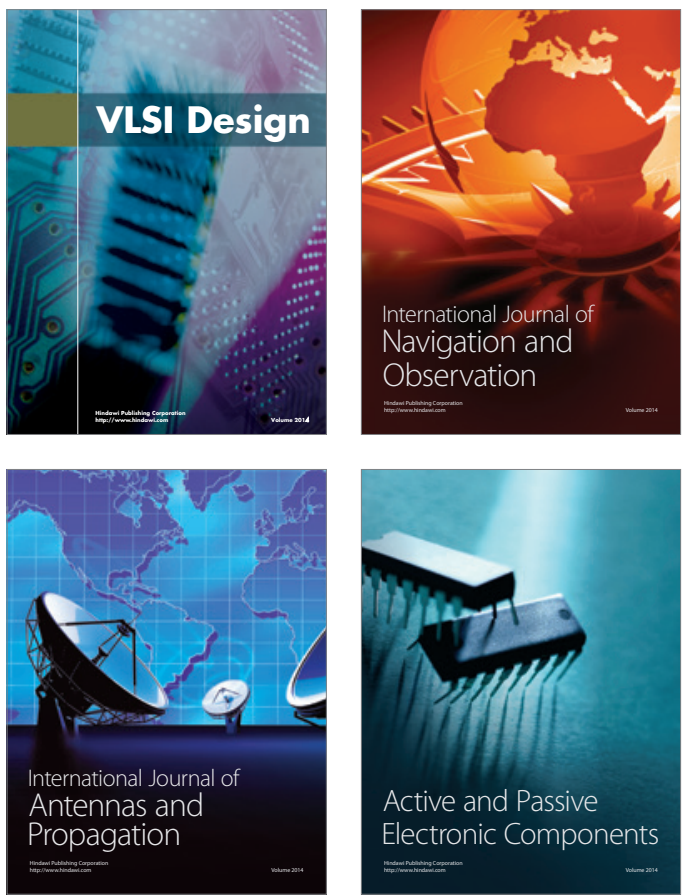
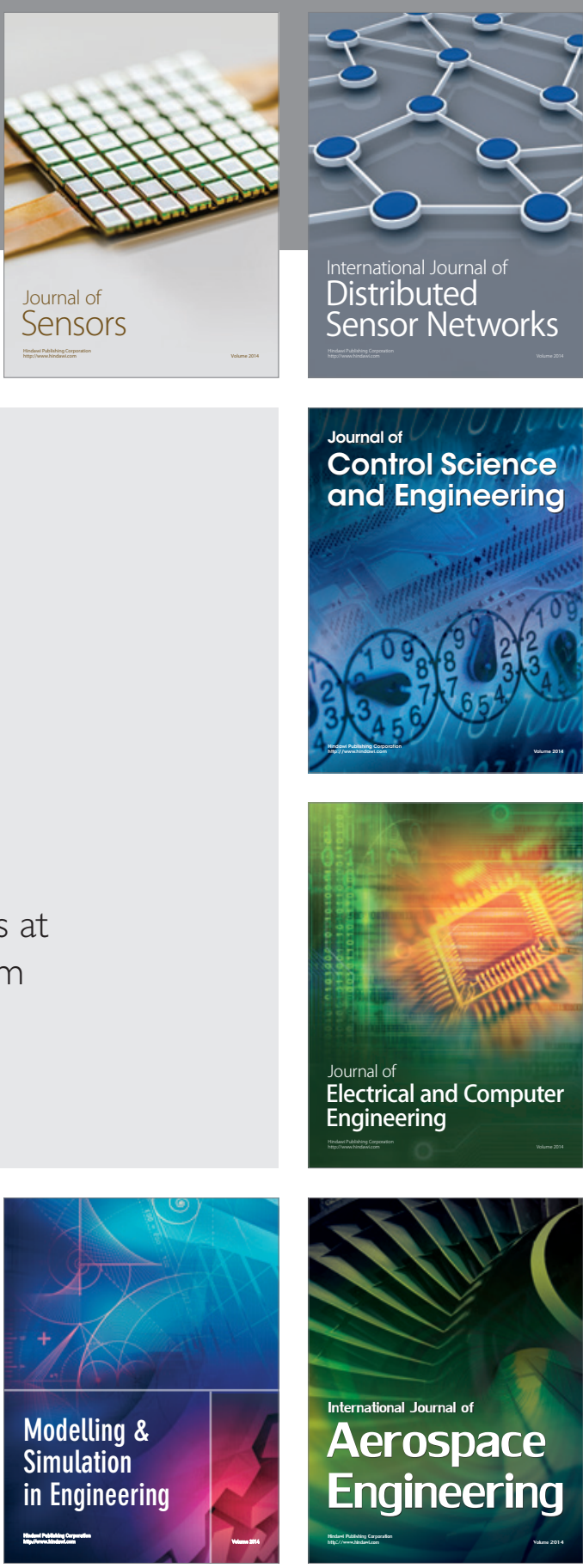

International Journal of

Distributed

Sensor Networks

Journal of

Control Science

and Engineering
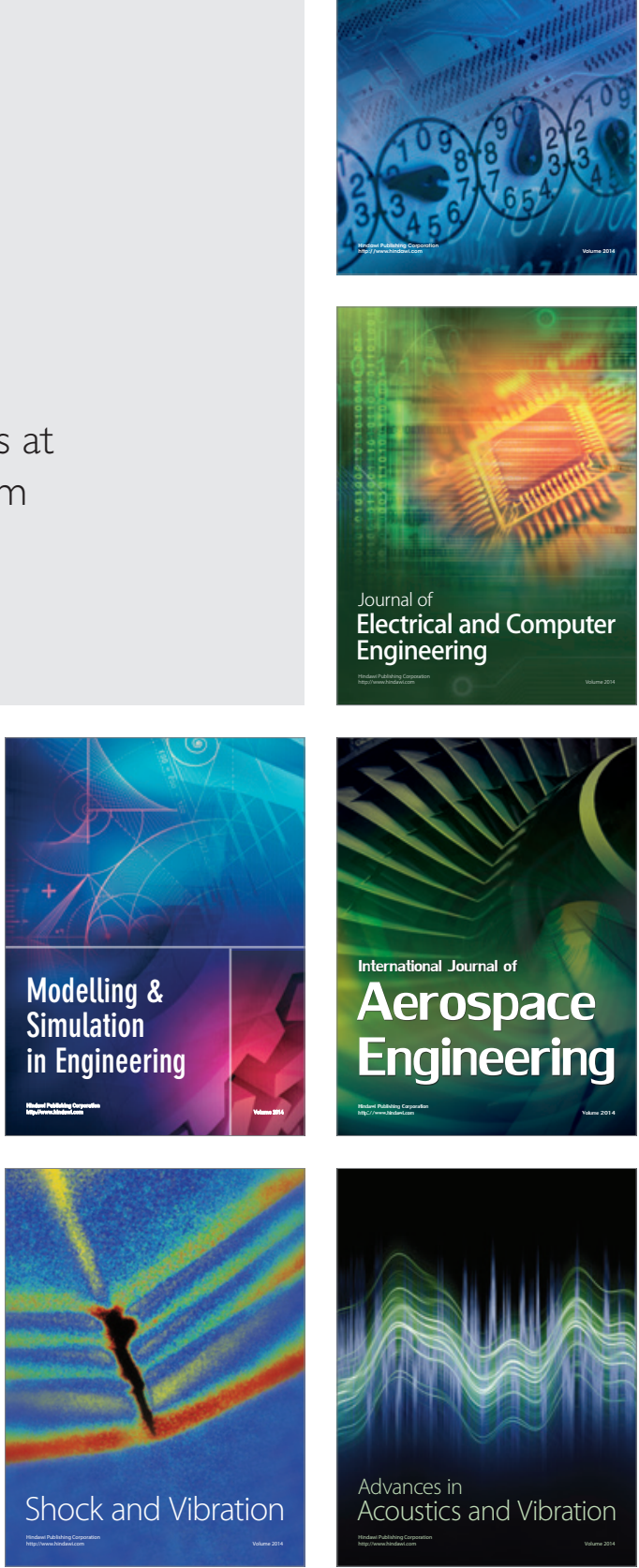